\title{
Zinc transporter-3 [SLC30A3 (rs11126936)] polymorphism is associated with major depressive disorder in Asian subjects
}

Munn-Sann Lye ${ }^{1 *}$, Aishah-Farhana Shahbudin ${ }^{1}$, Yin-Yee Tey ${ }^{1}$, Yin-Sim Tor ${ }^{1,2}$, King-Hwa Ling ${ }^{3}$, Normala Ibrahim ${ }^{4}$, Johnson Stanslas ${ }^{5}$, Su-Peng Loh ${ }^{6}$ and Rozita Rosli ${ }^{3}$

${ }^{1}$ Department of Community Health, Faculty of Medicine and Health Sciences, Universiti Putra Malaysia, 43400 UPM Serdang, Selangor, Malaysia.

${ }^{2}$ School of Bioscience, Faculty of Health and Medical Sciences, Taylor's University, 47500 Subang Jaya, Selangor, Malaysia.

${ }^{3}$ Department of Biomedical Science, Faculty of Medicine and Health Sciences, Universiti Putra Malaysia, 43400 UPM Serdang, Selangor, Malaysia.

${ }^{4}$ Department of Psychiatry, Faculty of Medicine and Health Sciences, Universiti Putra Malaysia, 43400 UPM Serdang, Selangor, Malaysia.

${ }^{5}$ Pharmacotherapeutics Unit, Department of Medicine, Faculty of Medicine and Health Sciences, Universiti Putra Malaysia, 43400 UPM Serdang, Selangor, Malaysia.

${ }^{6}$ Department of Nutrition and Dietetics, Faculty of Medicine and Health Sciences, Universiti Putra Malaysia, 43400 UPM Serdang, Selangor, Malaysia.

*Correspondence: Iyems9@yahoo.com; Tel.: +60-12-308-3186

Received: 10 May 2019; Accepted: 19 August 2019; Published: 13 September 2019

Edited by: Norshariza Nordin (Universiti Putra Malaysia, Malaysia)

Reviewed by: Rushita Bagchi (University of Colorado, USA); Azlina Ahmad Annuar (University of Malaya, Malaysia) https://doi.org/10.31117/neuroscirn.v2i3.34

ABSTRACT: Major depressive disorder (MDD) compromises the individual's capacity for self-care and productivity. Single nucleotide polymorphisms (SNP) of a number of genes have been associated with MDD. The zinc transporter-3 protein, encoded by the ZnT3 (SLC3OA3) gene, maintains zincglutamate homeostasis at the glutamatergic synapse, a disruption of which increases risk of MDD. We hypothesise that variation in SLC30A3 (rs11126936) SNP increases risk of MDD. We recruited 300 MDD cases and 300 controls, matched in the ratio of 1:1 by age, gender and ethnicity. PCRrestriction fragment length polymorphism analysis was used in DNA genotyping, validated by sequencing $10 \%$ of samples. Deviation from the Hardy-Weinberg equilibrium was tested using the chi-square test. Conditional logistic regression was used to estimate adjusted odds ratios, controlling for age, gender, ethnicity, occupation and family monthly income. Genotypes $G / G$ and $\mathrm{G} / \mathrm{T}$ showed two times greater odds of developing MDD compared to variant genotype T/T (OR=1.983, 95\% Cl=1.031-3.815; $\mathrm{p}=0.040$ and $\mathrm{OR}=2.232,95 \% \mathrm{Cl}=1.100-4.533 ; \mathrm{p}=0.026$ respectively). Carriers of genotypes G/G and G/T of the SNP rs11126936 in SLC30A3 are associated with increased risk of MDD. 
Keywords: depression; genetics; mood disorders; biological markers; zinc transporter (ZnT3) gene; SLC30A3 (rs11126936) SNP;

C2019 by Lye et al. for use and distribution in accord with the Creative Commons Attribution (CC BY-NC 4.0) license (https://creativecommons.org/licenses/by-nc/4.0/), which permits unrestricted non-commercial use, distribution, and reproduction in any medium, provided the original author and source are credited.

\subsection{INTRODUCTION}

Major depressive disorder (MDD) is a chronic disorder associated with high rates of non-recovery, recurrence and comorbidity [1]. DSM-5 defines MDD as "discrete episodes of at least 2 weeks' duration with clear-cut changes in affect, cognition, and neuro-vegetative functions, and inter-episode remissions" [2] ]. MDD adversely affects psychosocial function associated with reduced work productivity and days lost at work [2] and is the leading cause of disability in developed and developing countries, contributing to substantial health and economic burdens $[\underline{3}, \underline{4}]$. Depression when severe enough, compromises one's capability of self-care and independent living [5] and results in suicidal attempts in $4 \%$ of 19,723 inpatients reported in a systematic review [6].

The prevalence of MDD varies between $11.1 \%$ to $23.0 \%$ across different regions and populations [ㄱ-10]. According to the World Health Organization, $3.8 \%$ of the Malaysian population is affected by depressive disorders [4]. Local studies have reported the prevalence of depressive illness to be between $10.3 \%$ to $32.7 \%$ [11-15].

Genetic influence on the development of MDD is indicated by the heritability of between 40 to $75 \%$ [1621]. Single nucleotide polymorphisms of a number of genes such as tryptophan hydroxylase-1 (TPH1), tryptophan hydroxylase-2 (TPH2) gene and brainderived neurotrophic factor (BDNF) gene have been associated with MDD [22-26]. A point mutation in the SLC30A3 gene, particularly rs11126936 SNP, has been shown to be associated with schizophrenia in genomewide association studies [27] and low blood zinc levels [28]. The SLC3OA3 gene encodes for the zinc transporter-3 (ZnT3) protein [29], which "is the sole mechanism for concentrating zinc ions within synaptic vesicles in a subset of the brain's glutamatergic neurons" [30]. Zinc efflux and influx, controlled by zinc transporter genes, play a crucial role in zinc-glutamate homeostasis at the synaptic junction, which modulates the balance of excito-inhibitory impulses of the glutamatergic neurons $[\underline{31}, \underline{32}]$. Lower levels of ZnT3 have been found on autopsy in suicidal cases diagnosed with MDD [33]. Although there is extensive literature on blood zinc level and MDD, none have described the relationship between genetic variation of $\mathrm{ZnT3}$ and risk of MDD. This study aims to elucidate the effect of ZnT3 (SLC30A3 rs11126936) SNP on risk of MDD.

\subsection{MATERIALS AND METHODS}

\subsection{Ethics approval and consent to participate}

This study was approved by the Medical Research and Ethics Committee of the Ministry of Health Malaysia (NMRR No.: NMRR-14-688-19696). All recruited subjects gave written informed consent to participate.

\subsection{Study design and subject recruitment}

Three hundred case-control pairs matched on a 1:1 ratio by age ( \pm 5 years), gender and ethnicity, were recruited from psychiatry clinics in four public hospitals from 2014 to 2017. Cases included those who were 18 to 65 years of age diagnosed with single-episode non-psychotic Major Depressive Disorder (using the Diagnostic and Statistical Manual of Mental Disorders, Fifth Edition (DSM-5)) who presented with a history of MDD less than 2 years prior to recruitment.

Patients who had (i) significant suicidal risk as assessed by the psychiatrist at the point of inclusion, or diagnosed with (ii) dementia (iii) schizophrenia or other 
psychotic disorder (iv) bipolar I or II disorder, and (v) anxiety disorders including panic disorder, generalized anxiety disorder, obsessive-compulsive disorder and post-traumatic stress disorder were excluded from the study. Controls without a history of psychiatric disorders were recruited from patients attending otorhinolaryngology and ophthalmology clinics from the same hospitals where the cases were recruited. The sample size was estimated based on a power of $80 \%$, and a level of significance of 0.05 to detect an odds ratio of 2 or greater [34].

\subsection{Blood Collection}

Using evacuated EDTA tubes (Vacutainer Tubes, BectonDickinson, USA), $5 \mathrm{ml}$ of venous blood were collected from each subject and stored at $4^{\circ} \mathrm{C}$ prior to genomic DNA extraction within $24 \mathrm{~h}$.

\subsection{Genotyping of SLC30A3 rs11126936 SNP}

Genomic DNA was extracted from the buffy coat of the collected whole blood by using QIAamp DNA Mini and Blood Mini kit in accordance with the manufacturer's protocol (Qiagen, USA). Purity was determined using a NanoPhotometer ${ }^{\circ}$ Classic (Implen, USA) and the acceptable range for the ratio A260/A280 was 1.8-2.0.

Genotyping protocol was adapted from Fujihara et al. 2018 [28]. Oligonucleotide primers (both sense-F 5'-
TCCCAGAACCTCCACTCCTGGATCCTG- $3^{\prime}$ and antisense-R 3'-CCCCAGCTCTGGAATCTAGCCATCAGTTCT-5') were used to amplify the targeted SNP. Genotyping of SLC3OA3 rs11126936 was performed using polymerase chain reaction-restriction fragment length polymorphism (PCR-RFLP). A region of 146 bp carrying the polymorphic restriction sites of $M s p /$ was amplified in a $20 \mu \mathrm{l}$ PCR cocktail containing $100 \mathrm{ng}$ of genomic DNA. PCR composition, PCR condition, and RFLP digestion are listed in Table 1. Amplified fragments were subjected to RFLP analysis. Using the restriction endonuclease $\mathrm{Mspl}$, which cuts at $5^{\prime} \ldots \mathrm{C}^{\wedge} \mathrm{CGG} . . .3^{\prime}$, the variant (T/T) genotype [35] produced a single undigested product with $146 \mathrm{bp}, \mathrm{G} / \mathrm{T}$ genotype produced partially digested product with $146 \mathrm{bp}$, $109 \mathrm{bp}$ and $37 \mathrm{bp}$, while G/G genotype was fully digested into $109 \mathrm{bp}$ and $37 \mathrm{bp}$ fragments.

Ten percent of randomly selected PCR products were sequenced using ABI PRISM 3730xI Genetic Analyzer (Thermo Scientific, USA) to confirm accuracy of the genotyping method. The cycle sequencing reaction was performed following manufacturer's specifications (BigDye ${ }^{\circledR}$ Terminator v3.1 Cycle Sequencing Kit, Thermo Scientific, USA). The DNA sequence was then viewed on a sequence analysis software (Sequence Scanner Software 2.0, Thermo Scientific, USA).

Table 1. PCR composition, PCR condition, RFLP digestion of SLC3OA3 rs11126936 polymorphisms

\begin{tabular}{|c|c|}
\hline Polymorphisms & SLC30A3 (rs11126936) \\
\hline PCR composition & $\begin{array}{l}20 \mu \mathrm{L} \text { of total PCR reaction consisted of } 1 \mathrm{X} \text { DreamTaq green PCR mastermix with DreamTaq } \\
\text { DNA polymerase, } 1 \mathrm{X} \text { DreamTaq Green buffer, dATP }(0.4 \mathrm{mM}) \text {, dCTP }(0.4 \mathrm{mM}) \text {, dGTP }(0.4 \\
\mathrm{mM}) \text { and dTTP }(0.4 \mathrm{mM}) \text {, and } 4 \mathrm{mM} \mathrm{MgCl} \text { (Thermo Fisher Scientific, USA), } 10 \mu \mathrm{M} \text { of each } \\
\text { primer, } 100 \mathrm{ng} \text { of genomic DNA and nuclease free water. }\end{array}$ \\
\hline
\end{tabular}

$94^{\circ} \mathrm{C}$ for 3 minutes, followed by 30 cycles of denaturation at $96^{\circ} \mathrm{C}$ for 1 minute, annealing PCR condition at the melting temperature $63^{\circ} \mathrm{C}$ for 1 minute and extension at $72^{\circ} \mathrm{C}$ for 1 minute, with a final 10 min extension at $72^{\circ} \mathrm{C}$ and stored at $4^{\circ} \mathrm{C}$.

RFLP digestion $\quad \mathrm{U}$ of $\mathrm{Mspl}$ (New England Biolabs, USA) was prepared in nuclease-free water. The mixture was incubated at $37^{\circ} \mathrm{C}$ for 2 hours followed by 15 minutes at $65^{\circ} \mathrm{C}$. 


\subsection{Data analysis}

McNemar test was used to determine differences in sociodemographic variables between cases and controls using IBM Statistical Package for the Social Sciences (IBM SPSS) version 22. Conditional logistic regression (using STATA 10) was used to estimate odds ratios and $95 \%$ confidence intervals (Cls), controlling for confounding variables of age, gender, ethnicity, occupation, education and family monthly income. Statistical significance was set at alpha $=0.05$. Court Lab Calculator [36] was used to perform the chi-square test for deviations from Hardy-Weinberg equilibrium (HWE) for SLC3OA3 (rs11126936) gene polymorphism in the controls.

\subsection{RESULTS}

\subsection{Socio-demographic characteristics of cases and controls}

Significant differences were found between cases and controls $(p<0.05)$ in educational level, occupation, monthly income and family history of psychiatric illnesses. A higher proportion of controls (70.3\%) obtained tertiary education compared to cases $(51.0 \%)$ while MDD cases had lower monthly family incomes, where half of them earned less than RM 2,000 (USD 497.00) per month. In contrast to controls (4.7\%), a much higher proportion (26.7\%) of MDD cases had a family history of psychiatric illnesses while a greater proportion of controls worked in government or semigovernment sectors (40.3\%) (Table 2 ).

\subsection{Laboratory findings}

The representative images of the original gels are shown in Figure 1A. Ten percent of total samples from each genotype sent for sequencing were $100 \%$ identical with the results of PCR-RFLP. Figure 1B shows the partial sequence chromatograms of SLC3OA3 (rs11126936) polymorphism.

The genotypic distribution of SLC30A3 rs11126936 polymorphism for controls was T/T: $19 \%$ (57/300); G/T: 23\% (69/300); G/G: $58 \%$ (174/300) while for cases, it was T/T: $12.7 \%$ (38/300); G/T: $31.7 \%$ (95/300); G/G: $55.7 \%$ (167/300). SLC30A3 rs11126936 polymorphism deviated from Hardy-Weinberg Equilibrium ( $p<0.001$ ). Conditional logistic regression showed that subjects
(A)

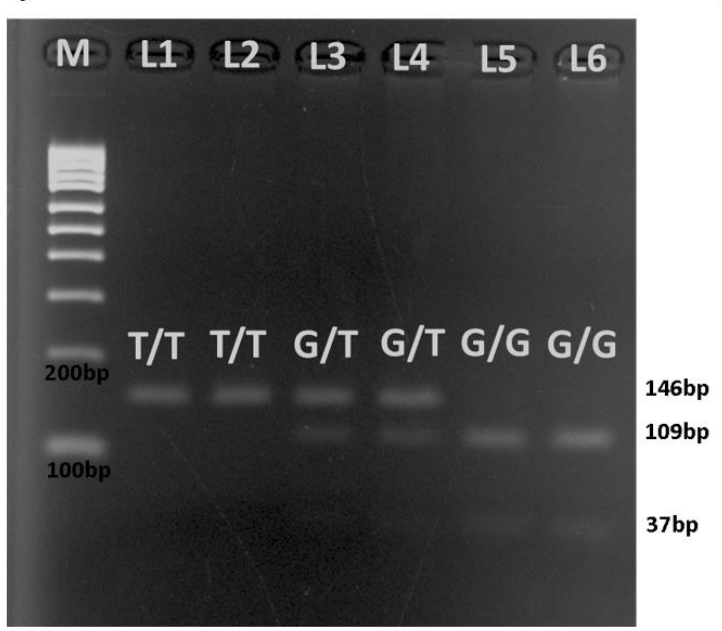

(B)

(i)

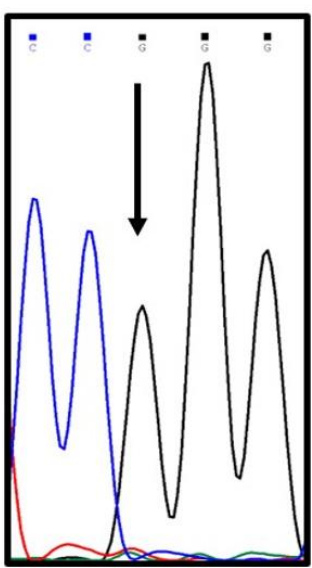

(ii)

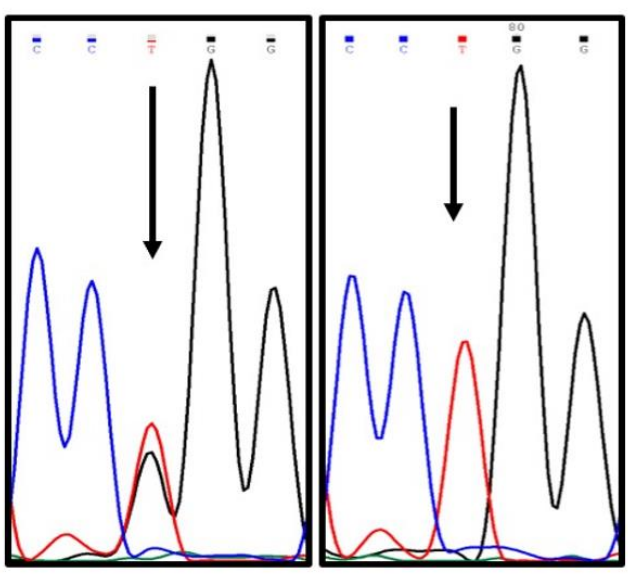

Figure 1. (A) Gel electrophoresis of PCR-RFLP products for SLC30A3 rs11126936 polymorphisms. M on the figure represents DNA ladder marker; L1 and L2 represent T/T genotype (146bp), L3 and L4 represent G/T genotype (146 bp, 109 bp and 37 bp); L5 and L6 represent G/G genotype (109 bp and 37 bp). (B) Partial sequence chromatograms of SLC30A3 rs11126936 polymorphism from study subjects. Arrow indicates the location of the nucleotide changes. Partial sequence chromatogram (i) represents G/G genotype; (ii) represents G/T genotype; (iii) represents T/T genotype. 
with genotypes $\mathrm{G} / \mathrm{T}$ (OR=2.23, 95\% $\mathrm{Cl}=1.10$ - 4.53; $\mathrm{p}=0.026)$ and $\mathrm{G} / \mathrm{G}(\mathrm{OR}=1.98,95 \% \mathrm{Cl}=1.03 \quad$ - 3.82; $p=0.040$ ) had two times higher odds of developing major depressive disorder compared to subjects with variant genotype $T / T$ after adjusting for age, gender, ethnicity, occupation, education and family monthly income. Those without a family history experienced a fifth of the odds of MDD (OR=0.18, 95\% $\mathrm{Cl}=0.09-0.36$; $\mathrm{p}=<0.001)$ compared with those with a family history (Table 3).

Table 2. Sociodemographic characteristics of the study population.

\begin{tabular}{|c|c|c|c|c|c|c|}
\hline \multirow{2}{*}{$\begin{array}{l}\text { Variables } \\
\text { Age (years) }\end{array}$} & \multicolumn{2}{|c|}{ Cases, $n=300 \%$} & \multicolumn{2}{|c|}{ Controls, $n=300(\%)$} & \multirow[t]{2}{*}{$x^{2}$} & \multirow[t]{2}{*}{$P$ value } \\
\hline & & & & & & \\
\hline $18-25$ & 52 & (17.3) & 55 & (18.3) & \multirow{5}{*}{4.675} & \multirow{5}{*}{0.320} \\
\hline $26-35$ & 76 & $(25.3)$ & 89 & (29.7) & & \\
\hline $36-45$ & 83 & $(27.7)$ & 62 & (20.7) & & \\
\hline $46-55$ & 48 & $(16.0)$ & 55 & $(18.3)$ & & \\
\hline $56-65$ & 41 & (13.7) & 39 & (13.0) & & \\
\hline \multicolumn{7}{|l|}{ Gender } \\
\hline Male & 97 & (32.3) & 97 & (32.3) & \multirow[t]{2}{*}{0.000} & \multirow[t]{2}{*}{1.000} \\
\hline Female & 203 & (67.7) & 203 & (67.7) & & \\
\hline \multicolumn{7}{|l|}{ Ethnicity } \\
\hline Malay & 149 & (49.7) & 149 & (49.7) & \multirow{3}{*}{0.000} & \multirow{3}{*}{1.000} \\
\hline Chinese & 90 & $(30.0)$ & 90 & (30.0) & & \\
\hline Indian and others & 61 & $(20.3)$ & 61 & $(20.3)$ & & \\
\hline \multicolumn{7}{|l|}{ Family income } \\
\hline$<$ RM 1000 & 87 & (29.0) & 28 & $(9.3)$ & \multirow{5}{*}{46.863} & \multirow{5}{*}{$<0.001^{\mathrm{a}}$} \\
\hline RM1001-RM2000 & 65 & $(21.7)$ & 57 & (19.0) & & \\
\hline RM2001-RM3000 & 64 & (21.3) & 74 & (24.7) & & \\
\hline RM3001-RM4000 & 25 & $(8.3)$ & 51 & (17.0) & & \\
\hline$>\mathrm{RM} 4000$ & 59 & $(19.7)$ & 90 & $(0.0)$ & & \\
\hline \multicolumn{7}{|l|}{ Education level } \\
\hline Primary/Secondary & 147 & (49.0) & 89 & (29.7) & \multirow{4}{*}{27.062} & \multirow{4}{*}{$<0.001^{\mathrm{a}}$} \\
\hline Certificate & 25 & $(8.3)$ & 27 & $(9.0)$ & & \\
\hline Diploma & 45 & $(15.0)$ & 82 & (27.3) & & \\
\hline Degree/Postgraduate & 83 & $(27.7)$ & 102 & (34.0) & & \\
\hline \multicolumn{7}{|l|}{ Family History } \\
\hline No & 220 & (73.3) & 286 & (95.3) & \multirow[t]{2}{*}{54.949} & \multirow[t]{2}{*}{$<0.001^{\mathrm{a}}$} \\
\hline Yes & 80 & $(26.7)$ & 14 & $(4.7)$ & & \\
\hline \multicolumn{7}{|l|}{ Occupation } \\
\hline Private & 85 & $(28.3)$ & 66 & (22.0) & \multirow{6}{*}{78.640} & \multirow{6}{*}{$<0.001^{\mathrm{a}}$} \\
\hline Government/ & 47 & (15.6) & 121 & (40.3) & & \\
\hline Semi-government & & & & & & \\
\hline Student & 41 & (13.7) & 64 & (21.3) & & \\
\hline Retired & 29 & (9.7) & 23 & $(7.7)$ & & \\
\hline Others & 98 & (32.7) & 26 & (8.7) & & \\
\hline
\end{tabular}

a $p<0.05$.

\subsection{DISCUSSION}

SLC30A3 rs11126936 (ZnT3 protein) is found abundantly in the brain, mostly in areas regulating emotions where glutamatergic neurons are distributed; namely the hippocampus, amygdala and frontal cortex [31, 37-39].
It was found that genotypes $G / G$ and $G / T$ was associated with twice the odds of MDD compared to the variant T/T. Fujihara et al. (2018) [28] postulated that increased expression of the SLC3OA family of genes might increase blood zinc levels. This is plausible as 
Table 3. Association of single nucleotide polymorphism of ZnT3 gene ( $r$ 11126936), with MDD using conditional logistic regression (239 cases and 263 controls).

\begin{tabular}{llllllll}
\hline Variables & & Crude OR & $\mathbf{9 5 \%} \mathrm{Cl}$ & $\mathbf{p}$ & $\mathbf{O R}^{\mathrm{a}}$ & $\mathbf{9 5 \%} \mathrm{Cl}$ & $\mathbf{p}$ \\
\hline SLC30A3 & $\mathrm{T} / \mathrm{T}^{\mathrm{b}}$ & 1 & & & 1 & & \\
(rs11126936) & $\mathrm{T} / \mathrm{G}$ & 2.1816 & $(1.2152-3.9165)$ & $0.009^{*}$ & 2.2324 & $(1.0995-4.5326)$ & $0.026^{\mathrm{c}}$ \\
& $\mathrm{G} / \mathrm{G}$ & 1.4075 & $(0.8345-2.3739)$ & 0.200 & 1.9834 & $(1.0311-3.8150)$ & $0.040^{\mathrm{c}}$ \\
\hline Family history & Yes & 1 & & & 1 & & \\
& No & 0.1430 & $(0.0754-0.2714)$ & $<0.001^{*}$ & 0.1771 & $(0.0867-0.3620)$ & $<0.001^{\mathrm{c}}$ \\
\hline
\end{tabular}

${ }^{a}$ odds ratio, adjusted by age, gender, ethnicity, family monthly income, occupation and education by conditional logistic regression.

${ }^{b}$ Variant genotype $(T / T)$ as reference for SLC3OA3 genotypes.

${ }^{c} p<0.05$.

SLC30A3 rs11126936 causes efflux of zinc ions out of the neurons, thus increasing zinc in the extracellular space. Fujihara et al. also found that the G/G genotype was associated with reduced blood zinc concentration [28].

A considerably higher proportion (26.7\%) of MDD cases had a positive family history of psychiatric illnesses compared to $4.7 \%$ in controls $\left(\chi^{2}=54.949, p<0.01\right)$. Sullivan et al. concluded in their meta-analysis that MDD is a familial disorder with heritability between $40 \%$ to $75 \%$ [16, 17, 19-21]. Although SLC3OA3 (rs11126936) SNP was not consistent with HWE, this is unlikely to be due to genotyping assay error as $10 \%$ of samples sequenced were in $100 \%$ concordance with RFLP results and the distribution for the genotypes of the SNP mentioned above in controls does not deviate towards an excess of heterozygotes [40]. Secondly, we do not think this is due to selection bias, as care was taken to recruit controls from the same hospitals as the cases so that the characteristics of controls would reflect those of the population from which cases arose. Thirdly, the deviation from HWE is likely due to "non-random mating" effect - leading to genetic segregation in which marriages within the same ethnicity or cultural background are still widely being practised in Malaysia [41]. Thus, the deviation from HWE does not preclude further analysis as the SNP may not be in equilibrium due to unidentified association with some other traits [40].
One of the potential limitations of the study could be selection bias introduced by the case-control study design. We have attempted to minimize this bias by recruiting controls from the same hospitals as the cases; differences in terms of sociodemographic characteristics were minimized by recruiting cases and controls matched by age, gender and ethnicity and also, by controlling for age, gender, ethnicity, family income, occupation and education by regression at the stage of data analysis.

\subsection{CONCLUSIONS}

Carriers of genotypes G/G and G/T of the SLC30A3 gene conferred twice the odds of MDD compared to the variant $\mathrm{T} / \mathrm{T}$. A significantly higher proportion $(26.7 \%)$ of MDD cases had a positive family history of psychiatric illnesses compared to $4.7 \%$ in controls. This study is an important first step to uncovering the effect of SLC3OA3 (rs11126936) polymorphism on the risk of MDD. To the best of our knowledge, this is the first report of SLC3OA3 (rs11126936) SNP increasing risk of MDD.

Acknowledgements: We thank the Director General of Health Malaysia for approval to publish this manuscript. We also thank Dr Azizul Awaluddin, Dr Sharifah Suziah Syed Mokhtar, Dr Mazni Mat Junus, Dr Elinda Tunan, Dr Ibrahim Mohammed Badamasi, Ms Aldoghachi Asraa Faris Abdulridha, Mr Khairul Aiman Bin Lokman, Ms Nurul Asyikin Abdul Razaq, Ms Siti Zubaidah Redzuan, Dr Vaidehi Ulanganathan, research 
assistants as well as the staff of the hospitals involved. The study was funded by Research Management Centre Universiti Putra Malaysia (GP-IPB/2013/9415700).

Author Contributions: M.S.L., K.H.L, N.I., J.S., S.P.L. and R.R. conceived and designed the experiments and obtained funding; A.S. and Y.S.T. performed the experiments; Y.Y.T and
M.S.L analyzed the data; M.S.L, K.H.L, N.I., J.S. and S.P.L. contributed reagents/materials/analysis tools; M.S.L, Y.Y.T, Y.S.T. and A.S. wrote the paper.

Conflicts of Interest: The authors declare no conflict of interest.

\section{References}

1. Greden JF. The burden of recurrent depression: causes, consequences, and future prospects. J Clin Psychiatry. 2001;62 Suppl 22(suppl 22):5-9.

2. Diagnostic and Statistical Manual of Mental Disorders (DSM-5 ${ }^{\circledR}$ ). Fifth edition. American Psychiatric Publishing, Incorporated; 2013. pp. 991, ISBN: 978-0-89042-554-1.

3. Collins PY, Insel TR, Chockalingam A, Daar A, Maddox YT. Grand challenges in global mental health: integration in research, policy, and practice. PLoS Med. 2013;10(4):e1001434. https://doi.org/10.1371/journal.pmed.1001434

4. World Health Organization. Depression and other common mental disorders: global health estimates. 2017.

5. Fried EI, Nesse RM. The impact of individual depressive symptoms on impairment of psychosocial functioning. PLOS ONE. 2014;9(2):e90311. https://doi.org/10.1371/journal.pone.0090311

6. Bostwick JM, Pankratz VS. Affective disorders and suicide risk: a reexamination. Am J Psychiatry. 2000;157(12):1925-1932. https://doi.org/10.1176/appi.ajp.157.12.1925

7. Patten SB, Williams JVA, Lavorato DH, Wang JL, McDonald K, Bulloch AGM. Descriptive epidemiology of major depressive disorder in Canada in 2012. Can J Psychiatry. 2015;60(1):23-30. https://doi.org/10.1177/070674371506000106

8. Fernandez-Pujals AM, Adams MJ, Thomson P, McKechanie AG, Blackwood DHR, Smith BH, et al. Epidemiology and Heritability of Major Depressive Disorder, Stratified by Age of Onset, Sex, and Illness Course in Generation Scotland: Scottish Family Health Study (GS:SFHS). PLoS ONE. 2015;10(11):e0142197. https://doi.org/10.1371/iournal.pone.0142197

9. Sund AM, Larsson B, Wichstrøm L. Prevalence and characteristics of depressive disorders in early adolescents in central Norway. Child Adolesc Psychiatry Ment Health. 2011;5:28. https://doi.org/10.1186/1753-2000-5-28

10. Avenevoli S, Swendsen J, He J-P, Burstein M, Merikangas KR. Major depression in the national comorbidity survey-adolescent supplement: prevalence, correlates, and treatment. J Am Acad Child Adolesc Psychiatry. 2015;54(1):37-44.e2. https://doi.org/10.1016/i.jaac.2014.10.010

11. Tan KL, Yadav H. Depression among the urban poor in Peninsular Malaysia: a community based crosssectional study. J Health Psychol. 2012;18(1):121-127. https://doi.org/10.1177/1359105311433908

12. Yee WS, Lin LP. Anxiety and depressive symptoms among communities in the east coast of Peninsular Malaysia: A rural exploration. Malays J Psychiatry. 2011;20(1).

13. Ibrahim N, Sherina MS, Phang CK, Mukhtar F, Awang H, Ang JK, et al. Prevalence and predictors of depression and suicidal ideation among adolescents attending government secondary schools in Malaysia. Med J Malaysia. 2017;72(4):221-227.

14. Sidik SM, Arroll B, Goodyear F. Prevalence of depression among women attending a primary urban care clinic in Malaysia. Singapore Med J. 2012;53:468-473. 
15. Maideen SFK, Sidik SM, Rampal L, Mukhtar F. Prevalence, associated factors and predictors of depression among adults in the community of Selangor, Malaysia. PLOS ONE. 2014;9(4):e95395. https://doi.org/10.1371/iournal.pone.0095395

16. Bierut $\amalg$, Heath AC, Bucholz KK, Dinwiddie SH, Madden PA, Statham DJ, et al. Major depressive disorder in a community-based twin sample: are there different genetic and environmental contributions for men and women? Arch Gen Psychiatry. 1999;56(6):557-563. https://doi.org/10.1001/archpsyc.56.6.557

17. Sullivan PF, Neale MC, Kendler KS. Genetic epidemiology of major depression: review and meta-analysis. Am J Psychiatry. 2000;157(10):1552-1562. https://doi.org/10.1176/appi.aip.157.10.1552

18. Levinson DF, Nichols WE. Major Depression and Genetics - Genetics of Brain Function - Stanford University School of Medicine. Available online: http://med.stanford.edu/depressiongenetics/mddandgenes.html (accessed on 26 June 2018)

19. Kendler KS, Pedersen NL, Neale MC, Mathé AA. A pilot Swedish twin study of affective illness including hospital- and population-ascertained subsamples: results of model fitting. Behav Genet. 1995;25(3):217-232.

20. McGuffin P, Katz R, Watkins S, Rutherford J. A hospital-based twin register of the heritability of DSM-IV unipolar depression. Arch Gen Psychiatry. 1996;53(2):129-136.

https://doi.org/10.1001/archpsyc.1996.01830020047006

21. Kendler KS, Prescott CA. A population-based twin study of lifetime major depression in men and women. Arch Gen Psychiatry. 1999;56(1):39-44. https://doi.org/10.1001/archpsyc.56.1.39

22. Hao R, Qi Y, Hou D-N, Ji Y-Y, Zheng C-Y, Li C-Y, et al. BDNF val66met Polymorphism Impairs Hippocampal LongTerm Depression by Down-Regulation of 5-HT3 Receptors. Front Cell Neurosci. 2017;11(1):306.

https://doi.org/10.3389/fncel.2017.00306

23. Lin Y-MJ, Ko H-C, Chang F-M, Yeh T-L, Sun HS. Population-specific functional variant of the TPH2 gene $2755 \mathrm{C}>\mathrm{A}$ polymorphism contributes risk association to major depression and anxiety in Chinese peripartum women. Arch Womens Ment Health. 2009;12(6):401-408. https://doi.org/10.1007/s00737-009-0088-z

24. Aldoghachi AF, Tor YS, Redzun SZ, Bin Lokman KA, Razaq NAA, Shahbudin AF, et al. Screening of brain-derived neurotrophic factor (BDNF) single nucleotide polymorphisms and plasma BDNF levels among Malaysian major depressive disorder patients. PLOS ONE. 2019;14(1):e0211241. https://doi.org/10.1371/journal.pone.0211241

25. Wigner P, Czarny P, Synowiec E, Bijak M, Białek K, Talarowska M, et al. Association between single nucleotide polymorphisms of TPH1 and TPH2 genes, and depressive disorders. J Cell Mol Med. 2018;22(3):1778-1791. https://doi.org/10.1111/icmm.13459

26. Froud A, Murphy J, Cribb L, Ng CH, Sarris J. The relationship between dietary quality, serum brain-derived neurotrophic factor (BDNF) level, and the Val66met polymorphism in predicting depression. Nutr Neurosci. 2017;22(7):513-521. https://doi.org/10.1080/1028415X.2017.1415281

27. Perez-Becerril C, Morris AG, Mortimer A, McKenna PJ, de Belleroche J. Allelic variants in the zinc transporter-3 gene, SLC30A3, a candidate gene identified from gene expression studies, show gender-specific association with schizophrenia. Psychiatry. 2014;29(3):172-178. https://doi.org/10.1016/i.eurpsy.2013.05.007

28. Fujihara J, Yasuda T, Kimura-Kataoka K, Takinami Y, Nagao M, Takeshita H. Association of SNPs in genes encoding zinc transporters on blood zinc levels in humans. Leg Med (Tokyo). 2018;30(0):28-33. https://doi.org/10.1016/j.legalmed.2017.10.009

29. Hediger MA, Clémençon B, Burrier RE, Bruford EA. The ABCs of membrane transporters in health and disease (SLC series): introduction. Mol Aspects Med. 2013;34(2-3):95-107.

https://doi.org/10.1016/j.mam.2012.12.009

30. McAllister BB, Dyck RH. Zinc transporter 3 (ZnT3) and vesicular zinc in central nervous system function. Neurosci Biobehav Rev. 2017;80:329-350. https://doi.org/10.1016/j.neubiorev.2017.06.006 
31. Petrilli MA, Kranz TM, Kleinhaus K, Joe $P$, Getz M, Johnson P, et al. The Emerging Role for Zinc in Depression and Psychosis. Front Pharmacol. 2017;8:414. https://doi.org/10.3389/fphar.2017.00414

32. Frederickson CJ, Suh SW, Silva D, Frederickson CJ, Thompson RB. Importance of zinc in the central nervous system: the zinc-containing neuron. J Nutr. 2000;130(5S Suppl):1471S-1483S.

https://doi.org/10.1093/in/130.5.1471S

33. McLoughlin IJ, Hodge JS. Zinc in depressive disorder. Acta Psychiatr Scand. 1990;82(6):451-453. https://doi.org/10.1111/i.1600-0447.1990.tb03077.x

34. Xiao Z, Liu W, Gao K, Wan Q, Yang C, Wang H, et al. Interaction between CRHR1 and BDNF genes increases the risk of recurrent major depressive disorder in Chinese population. PLOS ONE. 2011;6(12):e28733. https://doi.org/10.1371/journal.pone.0028733

35. National Center for Biotechnology Information. Reference SNP (refSNP) Cluster Report: rs11126936. Availabel online: https://www.ncbi.nlm.nih.gov/projects/SNP/snp ref.cgi?rs=rs11126936. (accessed on 12 July 2018)

36. Court M. Court Lab Calculator. Available online: https://www.researchgate.net/file.PostFileLoader.html?id=58dbf27a96b7e4fc194da329\&assetKey=AS\%3A47 7303651213312\%401490809466020. (accessed on 20 April 2018)

37. Paoletti P, Vergnano AM, Barbour B, Casado M. Zinc at glutamatergic synapses. Neuroscience. 2008;158(1):126-136. https://doi.org/10.1016/j.neuroscience.2008.01.061

38. Mlyniec K. Zinc in the Glutamatergic Theory of Depression. Curr Neuropharmacol. 2015;13(4):505-513.

39. Frederickson CJ. Neurobiology of zinc and zinc-containing neurons. Int Rev Neurobiol. 1989;31:145-238.

40. Turner S, Armstrong LL, Bradford Y, Carlson CS, Crawford DC, Crenshaw AT, et al. Quality control procedures for genome-wide association studies. Curr Protoc Hum Genet. 2011;Chapter 1:Unit1.19. https://doi.org/10.1002/0471142905.hg0119s68

41. Nagaraj S. Intermarriage in Malaysia. Malays J Econ Stud. 2009;46(1):75-92. 